\title{
DEBATES
}

\section{Da crítica da política à gestão pública eficaz: a despolitização como estratégia de poder}

\author{
From the criticism of politics to effective public management: \\ depoliticization as a political strategy
}

\section{Juliane Sant'Ana Bento}

\section{Resumo}

Os julgamentos da política municipal do Rio Grande do Sul fornecem elementos para se refletir em maior escala sobre as transformaçóes operadas na política pela definição que dela fazem os juristas. A hipótese que este trabalho mobiliza é de que a empresa de crítica da política protagonizada pelo sistema de justiça tem reforçado a estigmatização da política local como arcaica e patológica. Além disso, tem credenciado novos agentes, dotados de outros atributos antes externos à lógica política, enquanto sujeitos legitimados eleitoralmente a apresentar melhores soluçôes para a crise das administraçóes públicas. Este artigo descreve os resultados encontrados em estudo de caso sobre julgamento de prefeitos no referido estado com o objetivo de discutir a importação tardia da doutrina do new public management como modelo de gestão.

\section{Palavras-chave}

Julgamento da Política; Gestão Pública; Despolitização.

\section{Abstract}

The trials of local politicians in the state of Rio Grande do Sul provide us elements to reflect on a larger scale about the political changes and the new definition of politics made by jurists. The hypothesis mobilized is that the enterprise of politics criticism carried out by the Brazilian justice system has reinforced the stigmatization of local politics as archaic and pathological. In addition, it has accredited new agents, endowed with other attributes previously external to the political logic, as electorally legitimized to present better solutions to the crisis of public administrations. This article describes the results found in a case study on mayors trials in Rio Grande do Sul with the objective of discussing the late importation of the doctrine of "new public management" as a model.

\section{Keywords}

Political Trials; Public Administration; Depoliticization. 


\section{Introdução}

Este trabalho visa compreender os efeitos e problematizar um fenômeno em voga nas discussões contemporâneas sobre o Brasil: o descrédito da política ${ }^{1}$. Propóese aqui uma chave de leitura sobre o tema abordado: a deslegitimação da atividade política é resultado de uma construção social do problema do atraso institucional e democrático nacionais. No intuito de combater os males historicamente arraigados que supostamente se manifestam na política tradicional brasileira, o sistema de justiça, cada vez mais, vem oferecendo seus instrumentos, suas crenças e representações.

O sistema de justiça vem sendo protagonista de uma empresa crítica da política, alçando-se a instância de seleção e legitimação do modo correto pelo qual ela deveria ser exercida. A problemática que este artigo desafia é descrever as condiçóes de possibilidade para tal atuação, considerando o contexto híbrido e periférico observado, bem como compreender os efeitos sociais que promove no jogo político, agora transformado pela interferência da lógica judicial. A hipótese mobilizada para entender as causas dessa definição da política pelo direito consiste em privilegiar os princípios de estruturação social e as representaçóes dos universos práticos e simbólicos, muito mais do que características institucionais de independência e autonomia dos órgãos de justiça.

É achado recorrente no discurso dos agentes judiciais a necessidade do controle e da tutela da política, eis que degenerescente e patológica. Tal promoção de um ambiente de crise perene da política autoriza os juristas a intervirem, constituindo um verdadeiro modelo profissional pautado pela defesa moral da Constituição e do Estado de Direito e justificado pela neutralidade e técnica supostamente inerentes ao Direito. A partir de um estudo de caso sobre os julgamentos de crimes de prefeitos no estado do Rio Grande do Sul, o presente artigo traz à discussão elementos para se refletir sobre o paradigma de boa administração pública que resulta consagrado desse processo.

A ideia de decantação da política municipal faz emergir eleitoralmente a figura do gestor público, porta-voz das premissas do new public management, interessado nos resultados que a administração pública pode apresentar e

\footnotetext{
${ }^{1}$ Segundo pesquisa do Instituto Nacional de Ciência e Tecnologia, 77,8\% dos brasileiros afirmam não ter "nenhuma confiança" nos partidos políticos. Disponível em: <https://politica.estadao.com.br/ noticias/geral,descredito-nos-partidos-atinge-8-em-10-brasileiros,70002362978>. Acesso em 15 ago. 2018.
} 
comprometido com a eficácia dos serviços. Ou seja, o julgamento da política local resulta em certa estigmatização da política de pequenos municípios, porque desprovidos de grandes capacidades estatais: tendem a ser vistos como locus privilegiado das formas arcaicas de práticas políticas, o lugar por excelência dos vínculos anômalos tradicionais e atrasados, do personalismo e do patrimonialismo. Ao passo que reforça essa crença, a crítica da política local favorece outro perfil de político, que concentra investimentos em outros atributos hodiernamente mais valorizados. Com isso, credenciam-se à vida pública perfis de políticos que mobilizam um repertório que consiste em formaçáo escolar e profissional para a gestáo, combinado à circulação internacional em centros difusores de modelos de administração eficaz: a importação de tal modelo de despolitização da prática política local, no entanto, não pode escapar a uma análise de suas implicações para o jogo político.

\section{A patologia, a herança colonial e a crise politica: um repertório critico permanente}

As relaçóes e as redes pessoais sempre foram consideradas pelos pensadores do Brasil para compreender a ordem social, especialmente no que respeita a importância do poder privado como barreira à construção de uma ordem pública. A herança ibérica, a importância da família e dos laços pessoais, o privatismo, o mandonismo, o clientelismo e a patronagem política são todos elementos que perpassam os textos fundamentais sobre o Brasil ${ }^{2}$, que comungam o entendimento de que as redes personalistas envolvem uma pirâmide de relaçóes que atravessa a sociedade de alto a baixo, compondo, alegadamente, a "gramática política" do Brasil.

A natureza patológica da organização política, especialmente em se tratando do nível local, é tese recorrente no pensamento social brasileiro, a exemplo dos casos descritos por Briquet (1991 e 2007) ${ }^{3}$. Segundo as interpretaçóes mais difundidas, no Brasil o processo eleitoral é compatível com a manutenção dos privilégios das oligarquias locais, o que acaba por tornar a democracia "ornamental e declamatória"

\footnotetext{
${ }^{2}$ Nestor Duarte (1939), Oliveira Viana (1987), Sergio Buarque de Holanda (1995), Maria Isaura Pereira de Queiroz (1976), Victor Nunes Leal (1975), Raimundo Faoro (2012), Simon Schwartzman (1982), até o mais recente trabalho de Edson de Oliveira Nunes (2010).

${ }^{3}$ No caso da Córsega, a desqualificação das práticas políticas insulares pelas elites continentais, mais acostumadas com as práticas políticas "legítimas" exercidas na França continental. No segundo caso, como a "questão mafiosa" é formulada como um problema público na história da Itália unificada.
} 
(BUARQUE DE HOLLANDA, 1995, p. 183). A realidade histórica teria comprovado o "continuísmo das estruturas patrimoniais" (FAORO, 2012, p. 822), mesmo perante avançadas formas de representação, o que permitiu a conclusão da não-adaptação do sistema representativo à realidade brasileira, ou ainda, da cultura local retrógrada como um obstáculo à modernização política.

No entanto, entender o clientelismo como uma herança tradicional da sociedade brasileira, que dificulta sua institucionalizaçáo e prejudica o funcionamento do Estado a partir de uma ordem racional-legal e do universalismo de procedimentos é dar razão à tese, já superada, que estigmatizava como sociedade atrasada aquela que não conseguia impor os princípios democráticos aos personalistas. Restando já comprovada a dissociação entre burocratização e fim do clientelismo, e admitindo-se que as relaçóes pessoais seguem operando inclusive em sociedades centrais contemporâneas, manifesta-se a importância de observá-las enquanto código de significação de culturas locais (BRIQUET e SAWICKI, 1998), e em seus aspectos instrumentais, capazes de produzir modificações no modo como as estruturas formais operam (BEZERRA, 1995).

Partindo da hipótese de que o arcaísmo político é mobilizado por determinadas elites de publicistas para legitimarem-se no campo político a partir de seus capitais simbólicos, conjugando o domínio da "técnica" para justificar a ocupação de postos públicos - de onde atuam na condição de agentes autorizados a definir a boa-política -, este trabalho pretende reforçar a perspectiva de que a "racionalização" e "modernização" estatal dão-se paralelamente com a permanência dos vínculos de reciprocidade e a mobilização das redes pessoais entre esses agentes.

\section{Moralização da política e soluções técnicas}

Uma das formas eficazes de legitimação no espaço público tem sido a "cruzada pela moralização da política" que protagonizam os juristas, assim como no Brasil, fenômeno também percebido em várias conformaçôes sociais (MUSELLA, 2001; BRIQUET, 2001 e 2007; ROUSSEL, 2001 e 2002; VAUCHEZ, 2004). Oferecendo suas competências "técnicas" e "neutralidade" política para enfrentar as "patologias" da política brasileira, um grupo de juristas se instaura em postos de poder e se consolida como definidores da "boa política". Ou seja, a adesão à lógica da "moralização política" permite aos juristas a elaboração de conceitos e definições "técnicas" em doutrinas sobre o Estado, e os autoriza a mobilizar o "senso comum erudito", que considera a política tradicional desqualificada e atrasada. Esse processo de esvaziamento da política tradicional, porque viciada por interesses de grupos 
posicionados "contra o interesse público", conduz os juristas a manter ativa a lógica da construção dos problemas públicos, aos quais são cabidas suas soluçôes "técnicas" (BOURDIEU, 1986).

As empresas contestatórias da política estabelecida contribuíram a difundir o diagnóstico da degradação e a impô-lo como princípio explicativo da crise. Em virtude da exigência de mudança como um "necessário combate moral” em defesa da democracia e do Estado de direito, a fim de atender às reivindicaçôes de regeneração da vida pública, a magistratura foi dotada de uma capacidade de intervenção inabitual no espaço político.

A crítica da política é vivida pelos juízes como um exercício ordinário do dever profissional (ROUSSEL, 2002, p. 152; VAUCHEZ, 2004, p. 20). Mobilizando a necessidade de "redimensionamento das práticas administrativas" e da "reforma dos costumes políticos do estado", empreendem-se na construção de um novo saber sobre o Estado, que se destina a constituir uma nova verdade sobre o mundo social, diferente da versão "equivocada" da política praticada localmente.

Ao proporem-se a realizar um "efeito pedagógico forte" sobre a coisa pública (ALBUQUERQUE, 1999), põem em curso a "cruzada pela moralização" (BRIQUET e GARRAUD, 2001, p. 20) das atividades políticas, associadas genericamente ao paradigma da degradação, do atraso, do arcaísmo, das patologias herdadas, da falta de aptidáo para a modernidade e à democracia: um paradigma imposto como ortodoxia interpretativa. Em decorrência dessa premissa, reivindicam o "conhecimento correto" sobre o Estado e assumem para si o magistério da "boa política”, que sairia qualificada.

Os mecanismos de deslegitimação da política que fundamentam a abordagem moralizadora pelos tribunais conduzem os juristas a assumirem o papel de guarda da integridade do Estado democrático e a construírem modelos jurídicos que forneçam soluçôes, autorizados por sua tecnicidade e especialização nos julgamentos da política. O que os desembargadores do Rio Grande do Sul tratam por "inovadora engenharia institucional”, que foi criada a fim de dar conta de pôr "um fim à impunidade", é um bom exemplo de um controle político estável, contínuo e incisivo realizado desde o Judiciário (VAUCHEZ, 2004, p. 226).

O descrédito das elites dirigentes é perceptível também nos achados da bibliografia, como em Roussel (2002, p. 148), em que os magistrados passam a estigmatizar a "perda total do senso de honra", e tratam com desdém e repulsa social os agentes do poder político. Para um ministro do STF, alinhado a essa percepção, "o 
sistema político brasileiro, por vicissitudes diversas, tem funcionado às avessas: exacerba os defeitos e inibe as virtudes" (BARROSO, 2013, p. 214).

Vive-se no Brasil uma situação delicada, em que a atividade política desprendeu-se da sociedade civil, deixando de representá-la e, no limite, até de lhe servir. Quando isso ocorre, a política passa a ser um fim em si mesma, um mundo à parte, visto ora com indiferença, ora com desconfiança. Ao longo dos anos, a ampla exposiçáo das disfunçóes do financiamento eleitoral, das relaçóes oblíquas entre Executivo e parlamentares e do exercício de cargos públicos para benefício próprio trouxe uma onda de ceticismo que tem abatido a cidadania e minado a capacidade de indignação e de reação. A observação é de cunho institucional e não tem por foco qualquer governo em particular (BARROSO, 2013, p. 214, grifos da autora).

Caso similar pode ser encontrado na literatura, que entende "perder-se no tempo a compreensão da Política como ciência e arte relacionadas ao bom governo". Segundo o jurista, não se deve pensar "que a - constitua uma triste realidade de nossos dias, após um passado em que na arena política imperou a virtude e o espírito público". Para ele, engajado no "combate à degeneração da prática política" (RAMOS, 2004, p. 87-89).

trata-se, na verdade, de um mal endêmico entre nós, o que deveria, de há muito, ter afastado o simplismo voluntarista do campo de debates em torno do tema. Não resta dúvida, porém, de que, atualmente, as manifestações do fenômeno têm incomodado em maior grau a sociedade brasileira, o que é extremamente positivo, por representar, em alguma medida, o enraizamento da Democracia no Brasil, quer na perspectiva do exercício da liberdade de pensamento, principalmente por meio da imprensa, quer na perspectiva da vivência dos valores democráticos, que se antepóem ao amesquinhamento da atividade política (RAMOS, 2004, p. 91, grifos da autora).

No dizer de outro acadêmico do Direito, no Brasil, “as relaçóes promíscuas entre corruptor e corrompido manifestaram-se desde o Brasil colônia, continuaram no $1^{\circ}$ e $2^{\circ}$ Reinados, ingressaram na República e permaneceram até nossos dias, com maior ou menor intensidade de suas exteriorizações malignas no organismo da nação" (HORTA, 2004, p. 99). O raciocínio jurídico, muito amparado na ideia de "ética na 
política", sempre se fundamenta na "defesa intransigente" do "bem comum e da coisa pública”, por exemplo:

O administrador não é o senhor dos bens que administra, cabendo-lhe tão-somente praticar os atos de gestão que beneficiem o verdadeiro titular: o povo [...] Evitar que a corrupção se generalize e se torne sistêmica é dever de todos, o que importará na preservação de todas as instituiçôes dotadas de poder decisório e evitará que utilizem este poder de forma discricionária em favor de determinados grupos e em detrimento do interesse público (GARCIA e ALVES, 2013, p. 45).

Esse movimento de descrença dos canais tradicionais de mediação política e de deslegitimação dos atores políticos é também um processo de recomposição do jogo político e transformação do monopólio sobre a política, que antes era apanágio dos eleitos, em virtude de sua legitimidade eleitoral e popular, e agora vem sendo mobilizada como espaço dos juristas, em razão de sua legitimidade técnica, moral e especializada sustentada por um modo de recrutamento racional, baseado em concurso público, e instrumentalizado pelo direito. Em outras palavras, trata-se do repúdio aos políticos que dá lugar ao poder dos técnicos: a despolitização, a procedimentalização e codificação do que antes fora o espaço da política.

Vauchez (2004) chama atenção para o fato de a magistratura contribuir para desingularizar as práticas dos julgamentos da política, atribuindo qualidades intrínsecas às técnicas usadas nos processos. Seus usos em contextos novos confirmariam a validade geral, ao mesmo tempo em que suas expertises profissionais teriam validade estendida para outros casos.

Segundo Roussel (2002, p. 92), isso relaciona-se à concepção que fazem de si e do métier da Justiça como o lugar da "grandeza", a peça central para a democracia, a percepção de si como alguém que conta, que desempenha "algo nobre”. É a mídia, em grande parte, quem colabora para essa representação, quando valoriza a dignidade e a atividade dos juízes, produzindo um capital de "distinção eficaz" em relação ao mundo efêmero, comezinho e espaço dos interesses de grupos determinados da política.

\section{Aperfeiçoamento da administração e "novos" modelos de gestão}

O caso que origina a presente discussão aborda os julgamentos de crimes de prefeitos por uma Câmara Criminal especializada do Tribunal de Justiça do Estado 
do Rio Grande do Sul entre os anos de 1992 e 2016 (BENTO, 2017). O contexto de revisão da política pelos desembargadores é descrito por um dos componentes daquele colegiado de juízes como a promoção de uma "reforma nos costumes políticos do nosso Estado", uma vez que os prefeitos não seriam mais "imprudentes, negligentes no trato com o dinheiro público". Ou seja, a iniciativa judicial "redimensionou a administração pública, trouxe para a vida política do Rio Grande do Sul uma outra cultura, a cultura da probidade administrativa, do respeito pelo cidadão, pelo eleitor, respeito ao patrimônio público" (MACHADO, 2002, p. 202).

De fato, a organização e disposição institucional para instruir e julgar prefeitos terminou por criar uma rede de assessoramento e consultorias em direito público, visando a amparar as prefeituras, especialmente de cidades pequenas, que carecem de pessoal qualificado para administrar em conformidade com o aparato legal vigente "contra elas". Diz-se "contra" porque há certo argumento mobilizado entre os agentes políticos de que é impossível um prefeito terminar um mandato sem pelo menos uma conta impugnada ou um edital contestado.

Uma expressão da valorização dos especialistas e da importação de técnicas de gestão, em nosso campo de análise, é a publicação por um coordenador da Federação das Associações de Municípios do Rio Grande do Sul (FAMURS), - entidade municipalista de conhecida atuação em prol de temas e interesses políticos locais -, especialista em administração pública, ex-secretário de governo em dois municípios do Rio Grande do Sul, do que ele chama de "planejamento estratégico municipal". Segundo ele, hoje, as "diferenciadas formas de gerir um município demandam competências inexoráveis dos gestores públicos nas suas açôes frente a atual competitividade entre as cidades" (DORNELES, 2013, p. 13).

O planejamento estratégico associado a outras "boas práticas de administração pública baseadas na governança local participativa" seria recurso que permitiria enfrentar os "desafios contemporâneos": a "gestão socioambiental sustentável, a constituição de consórcios públicos e de outros instrumentos de gestão associada em políticas públicas, promover a identificação de vocaçóes locais e regionais, a definição de principais estratégias e políticas", por exemplo. Justifica a necessidade do "planejamento estratégico municipal", que ilustra o bom funcionamento a partir das experiências nas cidades de Porto Alegre, Curitiba, Belo Horizonte, Barcelona e Sevilha, além da "necessidade atual da conjuntura global" em alinhar "a gestão dos serviços públicos”, também na obrigação legal para municípios com mais de 20 mil habitantes, que disponham de um Plano Diretor (DORNELES, 2013, p. 16-17). 
Em narrativa sobre uma das "cidades-referência" mencionadas, Dorneles descreve um caso em que a introduçáo da "metodologia do planejamento estratégico situacional no sentido de apoiar a implantação dos projetos estratégicos do plano de governo [...] [permitiu o] desdobramento do planejamento estratégico em todos os órgãos da administração pública". Tal metodologia "incorpora a elaboração de cenários como ferramenta essencial para construir viabilidade ao planejamento", e pretende fundir "a dimensão política com a dimensão técnica". Exemplificando um "exercício prático de planejamento estratégico da gestão municipal”, o autor cita o "curso de capacitaçáo gerencial - Gestão para Resultados" destinado a mais de 600 "gerentes da Prefeitura", cujo conteúdo programático consiste em apresentar a ideia de "Arquitetura Estratégica": ou seja, "uma ferramenta objetiva para reflexão e reorientação estratégicas dos órgãos (DORNELES, 2013, p. 73).

Segundo o Dorneles (2013, p. 74), esse conjunto de práticas levou a uma ampla cultura de planejamento na administração pública da referida cidade e "desempenho para resultados", com a progressiva exigência de informaçóes sobre avaliação de resultados; de comunicação gerencial ágil que facilite a tomada de decisão; elaboração orçamentária com vistas a dar concretude ao planejamento e redação de um relatório anual com indicadores dos resultados.

Esse processo estudado, que atribui poder à racionalidade técnica, à invasão das normas de mercado e do mundo empresarial, à formalização do governo à distância e à intensificação das operaçôes de abstração, conforme Hibou (2012, p.18), constitui-se em crítica ao exercício do poder, dos modos de governo e das práticas de dominação. Este processo contemporâneo de "burocratização neoliberal", segundo a autora, é um conjunto de dispositivos normativos e procedimentais, uma forma social de poder e, também, um lugar de enunciação do político que configura a expressão da dominação atualmente.

A pertinência para o nosso objeto dá-se porque, quanto mais a legitimidade do político é questionada, segundo Hibou, mais formalizada será a institucionalização de procedimentos de "governança", a qual é traduzida por uma visão despolitizada e simultaneamente burocratizada da política, que "insiste sobre o formalismo jurídico e contratual e sobre uma visão de Estado de direito como instrumento de eficácia sócio-econômica”, e que explicaria o caráter central de reformas administrativas e manageriais. A participação, "a responsabilidade e os deveres políticos são agora redefinidos através da adoção de uma concepção muito formalizada da prestação de contas ou accountability" (HIBOU, 2012, p. 70). 
A melhoria do funcionamento da democracia estaria assegurada por procedimentos formais, que substituiriam o processo democrático, os debates e o trabalho de mediação política e social. Nesse contexto, agentes políticos transformamse em managers e "solucionadores de problemas", a partir do acesso a respostas técnicas e jurídicas. A inspiração do espaço privado mostra-se ainda pela transformação do cidadão em cliente, do "serviço público" em "serviço ao público" e por uma visáo "mercantilizada, tecnicizada e formalizada do político" (HIBOU, 2012, p. 71). Ademais, uma perspectiva de burocratização da participação implicaria ainda a "construçáo de consensos", promovido como "técnica de governo, regra de procedimento e modo de gestão", cujo objetivo consiste na rapidez e eficácia de decisôes insuscetíveis à contestação. Essa ideia que se difunde de "resolução de conflitos" mostrou-se instável e pouco eficaz, já que seu princípio é a construção de maiorias suficientemente fortes para submeterem minorias: promove um "governo sem política", bem traduzido pelo conceito de governança, além da eficácia e da responsabilidade das partes em um espaço marcado pelo apagamento dos conflitos e das relações de força (HIBOU, 2012, p. 72-73).

No processo de "desconflitualização", os agentes públicos não buscam mais fidelizar grupos sociais identificados, mas sim agregar interesses em torno de uma ação, algo que também é contemplado no trabalho de Cadiou (2009, p. 213). Para o autor, o exercício do poder local, hoje, exprime-se na capacidade em montar "grandes projetos”, em viabilizá-los, em realizar mesas redondas para financiar operaçóes, logo, a tratar de "problemas". Questiona-se sobre a representação do métier político fundada na competência gestionária com valor de presunção de legitimidade política. Sublinha que as equipes municipais, numa lógica de especialidades, contam cada vez mais com múltiplos profissionais da cidade, cuja preocupação gestionária, vinculada a saberes e competências técnicas, renova a identidade dos líderes políticos urbanos e modifica as exigências junto aos profissionais. $\mathrm{O}$ estilo político gestionário surgiria de um repertório que revela a impregnação de discursos estruturados por categorias de inspiração técnica, não mais partidária. Esse trabalho de estilizaçáo, por isso, promoveria o declínio de ofertas programáticas dos partidos sobre as políticas locais e, acima de tudo, um contexto de neutralização política (CADIOU, 2009, p. 215).

A respeito da desvalorização da legitimidade ligada à democracia representativa, e a crescente legitimidade managerial de que tratam também Boltanski e Chiapello (2009), Le Bart (2009) apresenta os agentes políticos locais situados entre esses dois mundos: o antigo mundo dos notáveis, que ainda os obriga às relaçóes de proximidade, mas agora também convidados a se posicionarem como managers e 
animadores de projetos, conscientes de valores como flexibilidade, abertura e mobilidade.

Le Bart concorda com Boltanski e Chiapello sobre como o eleito local está impregnado das lógicas conexionistas, que valorizam as redes abertas e leves em detrimento das instituições, cuja estabilidade é entendida negativamente, denunciada como esclerosada, pesada. Essa exigência do neo-capitalismo, segundo os autores, exige a disponibilidade à mobilidade geográfica, institucional, social e identitária, constituindo uma visão aberta e ofensiva do território, capaz de ser promovido e tornar-se atrativo, a fim de encontrar seu lugar no mercado concorrencial. As relaçóes de força estruturais são eufemizadas por contatos individuais e personalizados, fundados sobre confiança interpessoal e não mais sobre etiquetagem política. No entanto, o político notável tradicional, aquele que incarna e celebra o território, em razão da singular identidade local, que defende o território contra as empresas de desterritorialização, tem ainda sua legitimidade preservada por mobilizar ideologia comunitária que valoriza fidelidade, lealdade e o compromisso nas promessas (LE BART, 2009, p. 202).

A propósito da difusão da ideologia do new public management (NPM), típica dos governos Thatcher e Reagan, Lagroye et al. (2012, p. 497), afirmam que ela fornece uma linguagem e esquemas de pensamento comuns aos reformadores do Estado. A justificativa ideológica desse fenômeno corresponderia à afirmação de uma "necessidade": de tornar mais forte e mais eficaz o núcleo do Estado, livrando-o de tarefas secundárias, não essenciais, que o deixam mais vagaroso. $\mathrm{O}$ objetivo explícito de modificar radicalmente a função pública e a organização administrativa permite a um restrito grupo dominante monopolizar os postos mais elevados. A "racionalização e modernização", defendidas pelo NPM, aparecem no começo do século XXI como um poderoso sistema de crenças e de representaçóes que assegura a coerência intelectual das transformações nas práticas e representações de um "bom governo", associando governantes eleitos e altos funcionários, "aumenta a eficácia da burocracia e põe em estreita colaboração os eleitos e os administradores, revestidos de dupla legitimidade". Estabelece a legitimidade, portanto, de práticas de gestão e de concentração do poder de decisão, a partir da "ilusão bem fundada" de que daria os contornos de uma democracia, enfim, "livre de ideologias".

Segundo Lagroye et al. (2012, p. 561), para qualificar essa transformação decisiva dos modos de ação e do papel dos agentes do Estado, foi proposta a substituição do termo governo pelo termo "governança". Designa uma quantidade de 
processos nem sempre logicamente relacionados, entre os quais: redução de capacidades de controle das políticas pelos governantes; multiplicação e dispersão dos centros de decisão em escala internacional, nacional e local; surgimento de normas e regras, elaboradas "de baixo"; permeabilidade de fronteiras entre o público e o privado; e perda de legitimidade dos agentes políticos. Além disso, o custo elevado de medidas a tomar e do pessoal a contratar e formar, incita os governos a "externalizar as despesas", utilizando o pessoal de associaçóes e os recursos financeiros dos municípios e agentes privados: elogio ao voluntariado, glorificação de iniciativas da "sociedade civil", valorização de parcerias, tendendo a legitimar a diminuiçáo do poder público em assuntos nos quais ele deveria permanecer atuante. Desse modo, a nova concepção de critérios de excelência na política, tradução de suas próprias competências profissionais, legitima um novo estilo de ação e de governo, mais moderno e mais eficaz, e também mais democrático a seus olhos.

Nesse processo de crise da política local, soma-se outra ponderação elencada pela bibliografia: as relaçôes entre modelos exógenos e microcosmos sociais precisam ser problematizadas. Segundo os autores, são modelos exógenos os "dispositivos de gestão com pretensão universal" importados aos campos institucionais existentes, e microcosmos sociais as "constelações de atores locais e universos profissionais" suscetíveis de incorporar tais práticas e transformar organizaçôes. Demonstram, assim, como o Banco Mundial atua consagrando determinadas cidades como "casos de gestão exemplar", e prescrevendo "em nome da transparência e da eficácia, a generalização da participação do setor privado como remédio à crise financeira dos municípios" (BLANCHET e CCEURDRAY, 2010, p. 53).

Para além dos efeitos de dominação política que entidades filantrópicas fomentam, a internacionalização do campo da boa administração pública e do fornecimento de instrumentos e técnicas para controle de políticas e combate à corrupção gera uma circulação internacional de saberes e produtores de saber nesse campo científico emergente, tal como no caso descrito por Dezalay e Garth (2006). A rede de instituições em atuação em prol da defesa da boa administração pública mostra o fortalecimento de uma comunidade científica que se organiza como um mercado de exportação de expertise de pretensão universalista. Uma "nova ortodoxia savante" (DEZALAY e GARTH, 2006, p. 310) é construída, com vistas a uma estratégia de imperialismo simbólico: porém, ainda que de pretensôes mundiais, tais modelos encontram uma pluralidade táo grande de usos nacionais quanto mais variadas são suas implantações, ou seja, revelam verdadeira disjunção entre o discurso universalista e as suas traduções nacionais. 


\section{Considerações finais}

A estratégia de despolitização das práticas políticas locais, portanto, não se dá sem efeitos para o jogo político. Por todo o exposto, crê-se imprescindível que a agenda de estudos sobre a propalada crise da política local incorpore dentre seus objetos as implicações promovidas por tal importação recente dos modelos de administração eficaz.

Conforme a discussão apresentada, os perfis de agentes políticos que se tornam legitimados à vida pública tendem a ser dos que mobilizam o repertório relativo à gramática política da governança e da gestão, geralmente associados à escolarização e profissionalização mediada por centros difusores de tal modelo, com vínculos internacionais que os permitem acumular atributos reivindicando tal expertise. Modernidade e eficácia seriam os novos princípios de ação política legítima, a qual retira seu paradigma de excelência de atuação da tradução das próprias competências profissionais que prescreve. Como anunciam Dezalay e Garth (2006), a defesa da boa administração pública é devedora de uma rede de instituições e do fortalecimento de uma comunidade científica que se organiza como um mercado de exportação de expertise.

$\mathrm{Na}$ medida em que recrudesce a crítica dos agentes políticos e de seus modos tradicionais de desempenhar o métier, a bibliografia mostra que mais em voga se tornam os procedimentos e o léxico de gestão e governança. Ou seja, a crítica da política coloca a administração pública no centro de uma transformação: do que era seu método tradicional, de composição e resolução de conflitos, é transmutada para processos de formalização, burocratização e despolitização. Portanto, as reformas manageriais, cujos conteúdos consistem em reforçar o formalismo jurídico e uma visão instrumental de Estado de direito conduzem à promoção de um "governo sem política”.

Quanto àqueles modos tradicionais de se fazer política, orientados pela resolução de conflitos, passam a ser identificados à "instabilidade e baixa eficácia", segundo a nova representação do poder como governança, levando ao diagnóstico de que a construção de maiorias suficientemente fortes poderiam legitimamente submeter as minorias e apagar os conflitos de interesses. A "necessidade" de fortalecer e dar maior "eficácia" ao Estado justificaria ideologicamente a "ilusão bem fundada", como bem apontado por Lagroye (2012), de uma democracia, enfim, apolítica porque "livre de ideologias". 
- Juliane Sant'Ana Bento é Doutora em Ciência Politica pela Universidade Federal do Rio Grande do Sul (UFRGS). Professora no Departamento de Direito Público e Filosofia do Direito da UFRGS. E-mail: julianebento@ymail.com.

\section{Referências}

ALBUQUERQUE, Liège. Tribunal gaúcho condenou 92 prefeitos em 4 anos: 4a Câmara cuida apenas dos crimes de responsabilidade dos administradores municipais. In: O Estado de São Paulo, 5 de abr. de 1999.

ALMEIDA, Frederico. Justiça, combate à corrupção e política: uma análise a partir da Operação Lava Jato. In: Pensata, v. 5, n. 2, p. 69-82, 2016.

BARROSO, Luís Roberto. Fisiologismo, dinheiro e voto: uma proposta de reforma política para o Brasil. In: INSTITUTO VICTOR NUNES LEAL (Org). A contemporaneidade do pensamento de Victor Nunes Leal. São Paulo: Saraiva, 2013, p. 211-248.

BENTO, Juliane Sant'Ana. Julgar a política: lutas pela definição da boa administração pública no Rio Grande do Sul (1992-2016). Tese em Ciência Política. Programa de Pós-Graduação em Ciência Política. Universidade Federal do Rio Grande do Sul. 2017.

BEZERRA, Marcos Otavio. Corrupção: estudo sobre poder público e relações pessoais no Brasil. Rio de Janeiro: Relume-Dumará, 1995.

BLANCHET, Thomas; CEURDRAY, Murielle. Légitimités asymétriques et hybridations organisationnelles face à l'importation de pratiques étrangères: le secteur de l'eau en Allemagne. Critique internationale, v. 48, n. 3, p. 53-75, 2010.

BOLTANSKI, Luc; CHIAPELLO, Ėve. O novo espírito do capitalismo. São Paulo: Martins Fontes, 2009.

BOURDIEU, Pierre. La force du droit: eléments pour une sociologie du champ juridique. In: Actes de la recherche en sciences sociales. Vol. 64, p. 3-19, 1986.

BRIQUET, Jean-Louis. Les "primitifs" de la politique. La perception par les élites du vote en Corse sous la IIIe République. In: Politix. v. 4, n. 15, p. 32-47, 1991.

Mafia, justice et politique en Italie: l'affaire Andreotti dans la crise de la République (19922004). Paris: Karthala, 2007.

BRIQUET, Jean-Louis; GARRAUD, Philippe. Introduction. In: BRIQUET, J.-L.; GARRAUD, P. Juger la politique: entreprises et entrepreneurs critiques de la politique. Rennes: Presses Universitaire de Rennes, 2001. BRIQUET, Jean-Louis; SAWICKI, Frédéric. Le clientelisme politique dans les sociétés contemporaines. Paris: PUF, 1998.

BUARQUE DE HOLLANDA, Sérgio. Raízes do Brasil. São Paulo: Companhia das Letras, 1995. 
CADIOU, Stéphane. La politique locale: une affaire de techniciens? In: BIDÉGARAY, C.; CADIOU, S.; PINA, C. L'élu local aujourd'hui. Grenoble: PUG, 2009.

DEZALAY, Yves; GARTH, Bryant. Les usages nationaux d'une science "globale": La diffusion de nouveaux paradigmes économiques comme stratégie hégémonique et enjeu domestique dans les champs nationaux de reproduction des élites d'État. In: Sociologie du travail, v. 48, n. 3, 2006, p. 308-329.

DORNELES, Julio. Planejamento Estratégico Municipal: relevância, fundamentos e práticas a partir de experiências brasileiras e espanholas. São Leopoldo: Oikos, 2013.

DUARTE, Nestor. A Ordem Privada e a Organização Nacional: contribuição à Sociologia Política Brasileira. São Paulo: Companhia Editora Nacional, 1939.

ENGELMANN, Fabiano. Globalização e poder de estado: circulação internacional de elites e hierarquias do campo jurídico brasileiro. In: Dados, v. 55, n. 2 p. 487-516, 2012.

. Julgar a política, condenar a democracia? Justiça e crise no Brasil. In: Conjuntura Austral. Porto Alegre, v. 7, n. 37, p.09-16, 2016.

FAORO, Raymundo. Os Donos do Poder: formação do patronato político brasileiro. São Paulo: Globo, 2012.

GARCIA, Emerson; ALVES, Rogério Pacheco. Improbidade Administrativa. São Paulo: Saraiva, 2013.

HIBOU, Béatrice. La bureaucratisation du monde à l'ère néolibérale. Paris: La Découverte, 2012.

HORTA, Raul Machado. Política, Ética e o Controle Legal da Improbidade. In: ZILVETI, F. A.; LOPES, S. (Orgs). O Regime Democrático e a Questão da Corrupção Política. São Paulo: Atlas, 2004, p. 96-100.

LAGROYE, Jacques; FRANÇOIS, Bastien; SAWICKI, Frédéric. Sociologie politique. Paris: Dalloz, Presses de Sciences Po, 2012.

LEAL, Victor Nunes. Coronelismo, enxada e voto: o município e o regime representativo no Brasil. São Paulo: Alfa-Ômega, 1975.

LE BART, Christian. Les nouveaux registres de légitimation des élus locaux. In: BIDÉGARAY, C.; CADIOU, S.; PINA, C. L'élu local aujourd'hui. Grenoble: PUG, 2009.

MACHADO, Luiz Melíbio Uiraçaba. Depoimento [julho 1999]. In: FÉLIX, L. O. Histórias de Vida: entrevistas e depoimentos de magistrados gaúchos. Porto Alegre: Tribunal de Justiça do Estado do Rio Grande do Sul / Memorial do Judiciário do Rio Grande do Sul. v. 2, 2002, p. 179-213.

MUSELLA, Luigi. La classe politique en jugement: Tangentopoli et la critique de la politique en Italie. In: BRIQUET, Jean-Louis; GARRAUD, Philippe (Orgs.). Juger la politique: entreprises et entrepreneurs critiques de la politique. Rennes: Presses Universitaire de Rennes, 2001.

NUNES, Edson de Oliveira. A gramática política do Brasil: clientelismo, corporativismo e insulamento burocrático. Rio de Janeiro: Garamond, 2010.

OLIVEIRA VIANA, Francisco José. Instituiçóes Políticas Brasileiras. Belo Horizonte, São Paulo, Rio de Janeiro: Itatiaia, 1987.

QUEIROZ, Maria Isaura Pereira de. Mandonismo local na vida política brasileira. São Paulo: AlfaÔmega, 1976.

RAMOS, Elival da Silva. Ética e Política. In: ZILVETI, F. A.; LOPES, S. (Orgs.). O Regime Democrático e a Questáo da Corrupção Política. São Paulo: Atlas, 2004, p. 87-95. 
122

ROUSSEL, Violaine. Les magistrats dans les scandales politiques en France: logiques de action et jeux judiciaires locaux. In: BRIQUET, Jean-Louis; GARRAUD, Philippe. Juger la politique: entreprises et entrepreneurs critiques de la politique. Rennes: Presses Universitaire de Rennes, 2001.

. Affaires de juges: les magistrats dans les scandales politiques en France. Paris: La Découverte, 2002.

SCHWARTZMAN, Simon. Bases do autoritarismo brasileiro. Rio de Janeiro: Campus, 1982.

VAUCHEZ, Antoine. La institution judiciaire remotivée: le processus d'institutionnalisation d'une “nouvelle justice" en Italie. Paris: LGDJ, 2004.

Texto recebido em 16 de agosto de 2018. Aprovado em 24 de outubro de 2018. 